\title{
$\mathrm{CRM}$ 의 기능 분류를 위한 통계적 학습에 관한 연구
}

\author{
장 근 ${ }^{\dagger}$ 이 정 배 $^{\dagger+} \cdot$ 이 병 수 $^{\dagger+}$
}

요 약

\begin{abstract}
현재 ERP와 CRM은 대부분 전통적인 기능적 수행에만 초점이 맞추어져 있다. 그러나 최근의 경영환경은 인터넷(Internet)과 이를 기반으로 하는 전자상거래의 비약적 발전에 기인하여 시장의 변화를 가져왔으며, 이는 대부분 $\mathrm{e}$-비즈니스화되어 가고 있으며, 이를 추진하면서 제휴기관 과의 관계중진, 고객관계의 혁신적 개선은 물론 조직내부의 업무프로세스의 확기적 개선을 통한 경쟁력 강화를 적극적으로 전개하고 있다. $\mathrm{CRM(Customer} \mathrm{Relationship} \mathrm{Management)은} \mathrm{기업이} \mathrm{획득한} \mathrm{고객을} \mathrm{지속적으로} \mathrm{유지하고,} \mathrm{기업에} \mathrm{대한} \mathrm{고객의} \mathrm{가치를} \mathrm{증진시키기} \mathrm{위해} \mathrm{기업}$ 과 고객간의 상호 이익적 관계를 형성 유지 강화하려는 기업의 일련의 마케팅과정으로 다양하고도 수많은 고객둘의 정보를 기반으로 수행되기 때문에 고객 정보를 파악할 수 있는 시스템 기반을 필요로 하며, 생산과 상품의 천달경로, 마케팅, 그리고 의사결정 등의 경영 카테고리와 연관 되어 있다. 한편 ERP는 SCM과 CRM 및 SEM(Strategic Enterprise Management)둥으로 기능을 확대해감에 따라 21세기의 ERP는 e-비즈니 스의 전략적 도구로 발전해 갈 것이다. 본 논문에서는 이를 위한 중재 도구를 제시함으로써 고객에게 더욱 더 효율적이고 고 부가가치 있는 의 미 있는 데이터들의 퉁계적 기계 학습 법을 통해 CRM의 기능들을 효율적으로 분류할 수 있도록 한다. 또한 시스템 특징으로는 기존에 수작업 으로 이루어지던 파일의 분류 작업을 기계 학습법을 통한 에이전트가 자동으로 수행함으로써 사용자가 좀 더 효율적으로 작업을 수행 할 수 있도록 한 것이다.
\end{abstract}

\section{A Study of Statistical Learning as a CRM's Classifier Functions}

\author{
Keun Chang ${ }^{\dagger} \cdot$ Jung Bae Lee ${ }^{\dagger \dagger} \cdot$ Byoung Soo Lee ${ }^{\dagger \dagger}$
}

\begin{abstract}
The recent ERP and CRM is mostly focused on the conventional function performances. However, the recent business environment has brought the change in market due to the rapid progress of internet and e-commerce. It is mostly becoming e-business and spreading out as development of the relationship with other cooperating companies, the rapid progress of the relationship with customers, and intensification competitive power through the development of business progress in the organization. CRM(custom relationship management) is a kind of the marketing progress which forms, manages, and intensifies the relationship between the customers and companies to manage the acquired customers and increase the worth of customers for the company. It needs the system base which analyzes the information of customers since it functions on the basis of various information about customers and is linked to the business category such as producing, marketing, and decision making. Since ERP is extending its function to SCM, CRM, and SEM(strategic Enterprise Management), the 21 century's ERP develop as the strategy tool of e-business and, as the mediation for this, will subdivide the functions of CRM effectively by the analogic study of data. Also, to accomplish classification work of the file which in existing becomes accomplished with possibility work with an automatic movement with the user will be able to accomplish a more efficiently work the agent which in order leads the machine studying law, it is one thing with system feature.
\end{abstract}

키워드 : 전자상거래(ERP), 고객관계관리(CRM), 공급망관리(SCM), 평생고객가치(SEM), 베이지안, e-Commerce

\section{1. 서 론}

오늘날 시장경쟁이 점점 심화되고, 제품 및 서비스간의

※ 본 연구는 2003년도 인천대학교 학술연구 조성비 지원에 의하여 수행되었음

† 정 회 윈 : 인천대학교 정보기술대학 초빙교수

tt 종신회원 : 선문대학교 컴퓨터정보학부 교수

tft 종신회원 : 인천대학교 컴퓨터공학과 교수

논문접수 : 2003년 8월 21 일, 심사완료 : 2004 년 2월 6 일
차별성이 감소함에 따라 새로운 고객을 확보하거나 기존 고객을 유지하는 것이 매우 어렵게 되었다. 이에 기업들은 각 고객의 특성을 미리 파악하여 그 고객의 입맛에 맞는 제품 및 서비스를 제공함으로써 고객의 반응 정도를 향상 시키려는 노력을 하게 되었다. 즉, 시장점유율이 아니라, 기 업과 고객간의 우호적 관계 형성을 통한 고객점유율 향상 
에 마케텅 목표를 두는 것이다. 이러한 마케텅 수행방식을 관계마케팅(relationship marketing) 또는 고객 지향적 마케 팅이라 부른다. 이런 상황 속에서 최근 정보시스템의 호환 성에 대한 옥구를 반영하여 $\mathrm{ERP}$ (Enterprise Resources Planning; 전사적 자원관리) 시스템이 큰 각광을 받고 있 다. 또한 ERP는 개별 조직의 고유한 특성에 맞게 만들어진 것이 아니므로 조직이 도입하고자 하는 $\mathrm{ERP}$ 에 맞추어 완 전히 BPR(Business Process Reengineering)하거나, 아니면 $\mathrm{ERP}$ 를 각 조직의 환경과 특성에 맞게 조정하거나 필요한 모듈(module)만 구입하여 기존의 다른 시스템과 연결 사용 해야 한다[1]. 즉 현재의 $\mathrm{ERP}$ 는 조직이 필요로 하는 모든 욕구를 완벽하게 소화하기에는 다소 무리가 있다.

더구나 이러한 경영환경을 반영하여 최근 조직들은 전략 적 수단으로 $\mathrm{e}^{-}$비즈니스화를 적극 추진하면서 그 주된 구성 요소로 공급망관리(SCM : Supply Chain Management), 고 객관계관리(CRM : Customer Relationship Management) 및 $\mathrm{ERP}$ 등을 도입하려하고 있다. 한편 $\mathrm{ERP}$ 는 $\mathrm{SCM}$ 과 $\mathrm{CRM}$ 및 SEM(Strategic Enterprise Management)둥으로 확대되는 방향이 논의되고 구체화 됨에 따라 최근의 확장된 $\mathrm{ERP}$ 는 $\mathrm{e}^{-}$ 비즈니스 구축의 도구화가 되는 경향을 보이고 있기도 하 다. 지금까지 기업은 상품 또는 서비스를 보다 더 저렴한 가 격 또는 우수한 품질로 고객에게 제공함으로써 수익을 추구 했다. 그러나, 소비자의 요구가 다양해지고, 기업활동의 순환 사이클이 빨라지면서 기업은 더 이상 품질 또는 가격만으로 는 차별화 된 경쟁수단을 가질 수 없게 되었다. 기업은 고객 별로 적합한 상품 또는 서비스를 보다 신속히 제공하여야 기 업의 경쟁력을 가질 수 있으며, 고객을 정확히 이해하여 고 객과의 관계를 지속적으로 유지하는 것이 중요하게 되었다.

본 연구는 확장된 $\mathrm{ERP}$ 의 개념과 기능을 중심으로 $\mathrm{e}^{-}$비 즈니스 도입수단으로서의 $\mathrm{ERP}$ 의 가능성을 탐색하고 $\mathrm{CRM}$ 의 중재를 담당할 수 있는 도구로 에이전트의 기술을 도입 하여 자율성을 극대화하는데 초점을 두었다. 이를 위해 먼 저 확장된 $\mathrm{ERP}$ 의 개념과 기능을 점검하고 이와 $\mathrm{e}^{-}$비즈니 스의 필요기능을 비교함으로써 $\mathrm{ERP}$ 의 $\mathrm{e}^{-}$비즈니스 도구로 서의 적용가능성을 논의하였다. 또한, CRM의 도입 배경과 개인과 회사간의 경영 활동, 회사와 회사간의 겅영 활동에 중재 역할을 하는 에이전트의 도입 가능성을 논의하였다. 이러한 연구목적과 논의에 따라 $\mathrm{ERP}$ 와 $\mathrm{CRM}$ 시스템이 추 구해야 할 기능과 역할에 대해서도 논할 것이다. 또한 가장 바람직한 자율성의 보장과 탐색의 효율성을 높이기 위해 에이전트의 필요성에 대해서도 논한다.

\section{2. e-Business 응용기술을 이용한 CRM}

\section{1 e-Business모델과 주요기능}

인터넷의 등장은 산업이나 업계의 비즈니스 관행을 시공 을 초월해 저렴한 비용으로 24시간 가능하게 해주었다. 인 터넷이라는 매체의 특성을 활용한 전자상거래의 등장이 바 로 이 연장선이며, 이는 기업과 소비자간(BtoC) 전자상거래 로부터 기업간(BtoB) 전자상거래로 확대 발전해가고 있다 고 볼 수 있다. 더구나 중소형 기업들도 $\mathrm{ERP}, \mathrm{SCM}, \mathrm{CRM}$ 같이 대기업 위주로 진행되어 오던 기업의 정보화를 추구 하고, 거래기업과의 문서나 정보를 교환하기 위한 네트워크 를 저렴하고 효율적인 인터넷에 의해 쉽게 구축할 수 있게 됨에 따라 기업의 $\mathrm{e}^{-}$비즈니스화 기반은 매우 견고해 있다 고 할 수 있다. 따라서 $\mathrm{e}^{-}$비즈니스 모델의 분석은 (1) 전자상 거래와 지식경영(knowledge Management)의 토대 위에서 이루어지는 기업의 경영혁신 과정과 (2) 기업이나 산업의 가 치사슬을 구성하는 업무활동을 가지고 살펴볼 수 있다.

$\mathrm{e}^{-}$비즈니스모델의 근간은 윕 공간에서의 전자상거래이다. 전자상거래를 근간으로하여 비즈니스를 수행하기 위해서는 무엇보다도 지식경영의 틀 하에서 최선의 실행방안을 찾고 이를 전자적으로 수행할 수 있어야 할 것이다. 조직이 수 행하는 업무처리 프로세스는 크게 세 가지 축으로 나누어 설명 가능하다. 먼저 고객과의 관계를 최선의 방향으로 이끌 어가기 위해서는 통합고객관리(CRM : Customer Relationship Management) 모듈이 필요하며, 다음으로 내부업무 프 로세스의 효율화를 위한 전통적안 기능중심의 ERP 모듈이 필요하며, 마지막으로 파트너와의 관계강화를 위한 공급망 관리(SCM : Supply Chain Management) 모듈이 필요하다.

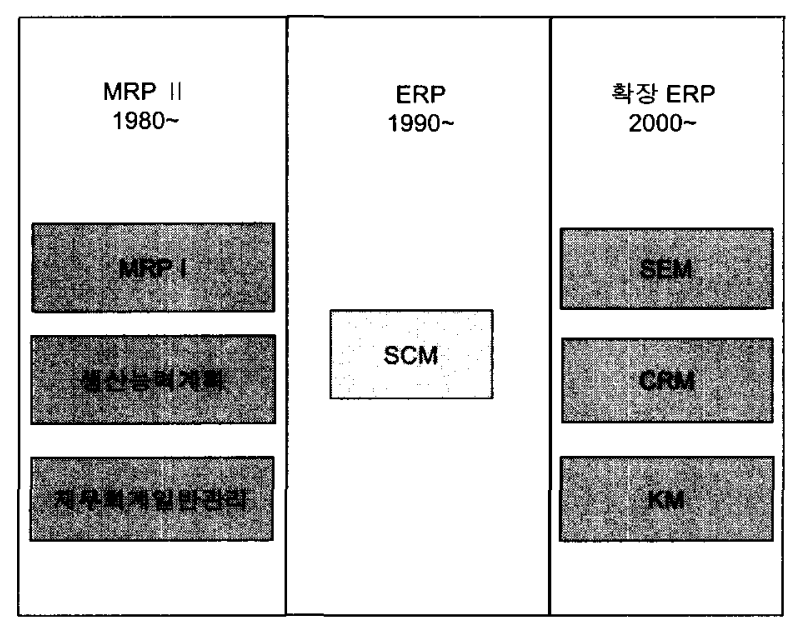

자료원 : 오라클 세미나 자료, 1999. 변형

(그림 1) ERP 개념과 기능의 확장과정 
통합고객관리(CRM)시스템은 신규 고객의 확보, 기존 고 객의 이탈 방지, 우수고객 유지, 고객가치 증진, 잠재고객 활성화, 평생 고객화 등의 고객관리 전략 차원에서 최근에 인기를 모으고 있다. $\mathrm{CRM}$ 은 수읙성이 높은 고객의 유지와 충성 고객의 확보를 통해 기업의 경쟁우위 확보 및 지속적 인 고객유치를 목표로 현재 고객과 잠재고객에 대한 자료 를 지속적으로 수집하여, 쓸모 있고 가치 있는 마케팅 정보 로 변환하고, 이를 이용하여 고객 행동을 분석/예측 및 고 객 세분화를 통해 고객별, 그륩별로 효과적이고 효율적인 마케팅 프로그램과 전략을 개발, 검증, 구현, 측정 및 수정 하는 일련의 과정으로서 $\mathrm{BtoC}$ 기반이라 할 수 있다.

반면 공급망관리 $(\mathrm{SCM})$ 는 공급체인 전체를 하나의 통합 된 개체로 보고 이롤 최적화하고자 하는 경영방식으로서, 최종 고객에게 최상의 제품이나 서비스를 가장 유리한 조 건으로 공급하기 위하여 공급업체로 구성된 공급망의 관리 를 의미하며 이는 완제품, 반제품 및 부품 등의 물류흐름에 대한 통합적인 관리 시스템으로서 $\mathrm{BtoB}$ 전자상거래 기반이 라 할 수 있다.

\section{2 $\mathrm{CRM}$ 의 개념과 기능}

지금까지 기업은 상품 또는 서비스를 보다 더 저렴한 가 격 또는 우수한 품질로 고객에게 제공함으로씨 수익을 추 구했다. 그러나, 소비자의 요구가 다양해지고, 기업 활동의 순 환 사이클이 빨라자면서 기업은 더 이상 품질 또는 가격만 으로는 차별화 된 경쟁수단을 가질 수 없게 되었다. 기업은 고객별로 적합한 상품 또는 서비스를 보다 신속히 제공하 여야 기업의 경쟁력을 가질 수 있으며, 고객을 정확히 이해 하여 고객과의 관계를 지속적으로 유지하는 것이 중요하게 되었다. CRM(Customer Relationship Management)은 기업 이 획득한 고객을 지속적으로 유지하고, 기업에 대한 고객 의 가치를 증진시키기 위해 기업과 고객간의 상호 이익적 관 계를 형성 유지 강화하려는 기업의 일련의 마케팅과정으로 정의될 수 있다. 물론 $\mathrm{CRM}$ 은 다양하고도 수많은 고객들의 정보를 기반으로 수행되기 때문에 고객 정보를 파악할 수 있는 시스템 기반올 필요로 하며, 생산과 상품의 전달경로, 마케팅, 그리고 의사결정 등의 경영 카테고리와 연관되어 있다. 이처럼 $\mathrm{CRM}$ 은 바로 고객과 기업과의 관계를 바탕으 로 평생 고객 가치인 LTV(Life Time Value)를 극대화하는 것으로 귀결된다. 그러나 단순히 고객과의 관계에 머무르지 않고 신규고객 및 기존 고객의 다양한 고객 접점(영업 사원, $\mathrm{A} / \mathrm{S}$ 직원의 방문, Inbound call, Outbound call, 인터넷 등)
을 활용하여 여기서 발생한 수많은 데이터를 정리 분석해 마 케팅 정보로 변환함으로써 고객의 구매 관련 행동을 지수화 하고, 이를 바탕으로 마케팅 프로그램을 개발, 실현, 수정하 는 고객 중심의 경영 기법이다. $\mathrm{CRM}$ 을 위해서는 상품/서비 스 중심으로 통합되어 있는 기업의 데이터를 고객 중심으로 통합을 한 뒤 여러 기법을 이용하여 기업 내외부의 고객정 보(인구통계정보, 거래이력 및 반응정보 등)를 분석하고 고 객을 세분화한다. 이를 통해 고객은 우량고객 집단, 휴면고 객 집단, 잠재 고객 집단 등 여러 특성 집단으로 분류가 될 수 있고, 기업은 각 특성 집단별로 차별화 된 마케팅믹스 전략을 수립할 수 있다. 각 고객 집단은 이렇게 기업이 실 시한 마케팅에 어떤 반응을 보일 것이고, 기업은 다시 이 반응 정보들을 분석하여 다음의 고객 정보 수립에 반영하 는 피드백을 수행한다.

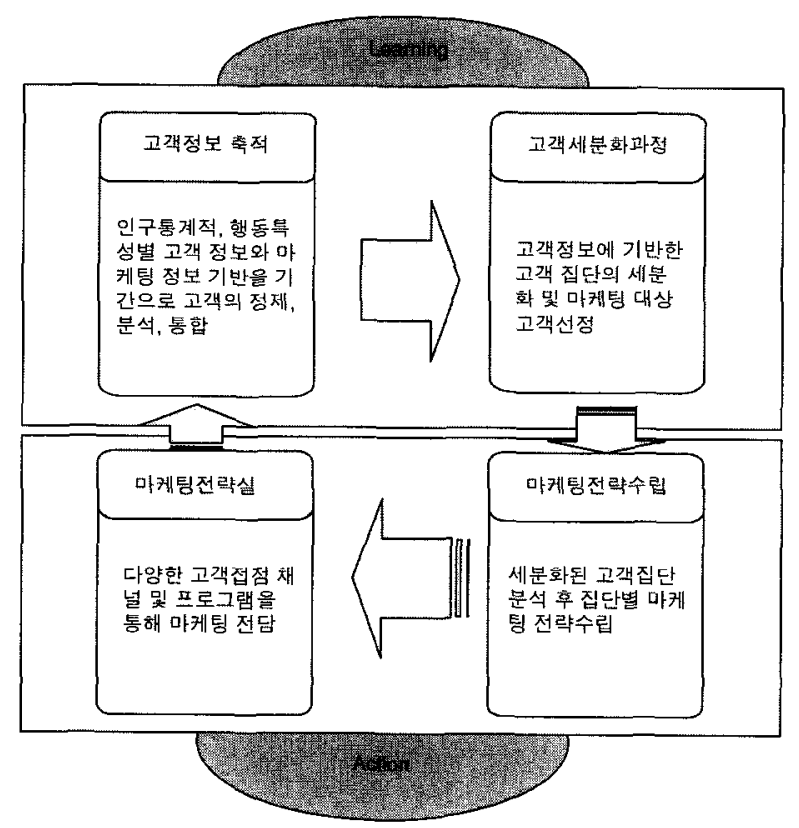

(그림 2) $\mathrm{CRM}$ 의 Closed Loop Management

$\mathrm{CRM}$ 프로세스에서 인식되어야 할 기본 사항들로는 첫째 로 고객과의 계속적인 Communication 및 관계지속을 통한 고객 이해가 필요하다. 둘째로 고객확보/유지 및 고객의 LTV 향상을 목표로 고객의 행동에 영향을 주기 위한 반복적/전 사적인 접근이 이루어져야 한다. 고객정보획독, 고객 세분 화, 마케팅전략의 수립, 실행 및 평가에 이르기까지 일련의 과정을 피드백 관리함으로써 지속적 개선을 해야 한다. $\mathrm{CRM}$ 은 기업이 수동적인 자세에서 벗어나 적극적으로 고객 을 유치하고 고객과의 관계롤 긴밀하계 이끌어가야 한다는 사업전략에서 비롯되었으며, 업무 프로세스 개선이 우선이 
다. CRM을 구현하기 위해서는 하드웨어, 소프트웨어, 네트 워크 장비분만 아니라, 전산자원을 통합하는 작업과 컨설팅 이 뒤따라야 하므로 CRM을 단순히 하드웨어나 데이터웨어 하우스의 연장선 또는 솔루션으로 파악해서는 안된다.

\section{3. 통계적 학습}

에이전트의 학습 문제는 전통적인 통계 기법에 의해서 잘 해결될 수 있는 것도 있다. 특하 평균이나 분산 같은 기 본적인 통계치나 확률 밀도 추정, 회기 분석, 주성분 분석, 마코프 모델 등은 다른 학습 알고리즘과 관련하여 유용하 게 사용될 수 있다. 통계 모델은 다른 학습 알고리즘들에 비해 비교적 잘 검증된 이론예 기반 하므로 문제의 가정과 잘 맞는 경우에는 신뢰성이 높고 비교적 단순한 계산 과정 을 톻해 적용될 수 있다는 장점이 있다. 그러나 많은 실제 적인 문제에 있어서는 이러한 가정이 만족되지 않는다. 유 사성을 추정하기 위해 차주 사용되는 간단한 방법은 상관 계수이다. 이 값은 두 확률 변수의 의존도를 나타낸다. 이 학습 기법은 메모리 기반 학습 기법이며 Lazy 학습 알고리 즘이라고도 한다. 이는 학습을 위한 훈련 예제를 메모리에 저장하여 차후에 분류 대상 문서를 입력 받아 분류할 때 모든 계산이 수행되기 때문이다. 통계를 기반으로한 대표적 인 학습 기법으로는 k-NN(k-Nearest Neighbor)학습 기법 이 있다. 이 방법은 분류 시에 분류 할 문서 $\mathrm{Y}$ 와 젓장된 클래스별 훈련 예제 $\mathrm{X}$ 와의 거리를 식 (1)에 의해서 계산한 다음 분류 대상 문서 $\mathrm{Y}$ 와 가장 가까운 $\mathrm{k}$ 개의 훈련 예제 $\mathrm{X}$ 를 선정한다.

$$
D_{x y}=\sqrt{\sum_{i=1}^{n}\left(X_{i}-Y_{i}\right)^{2}}
$$

그리고 선정된 $\mathrm{k}$ 개 중에서 가장 많은 개수의 클래스별 훈련 예제가 소속된 부류로 분류 대상 문서 $\mathrm{Y}$ 가 분류된다. 여기서 $\mathrm{i}$ 는 클래스의 종류이며 $\mathrm{n}$ 은 클래스의 개수이다. $\mathrm{k}$ 값 은 $\mathrm{k}-\mathrm{NN}$ 기법의 성능을 쵝적화 하기 위하여 일반적으로 cross validation 기법을 사용하여 사전에 결정하며 $\mathrm{k}=1$ 인 경우를 NN기법이라고 한다. 위에서 사용한 확룰 모델은 이 미 알고 있는 지식을 사전 지식으로 사용하여 학습 목표인 조건부 확룰을 계산하는 베이스 정리(Bayes theorem)에 그 기초를 두고 있다. 실제 분류 문제에 가감 많이 사용하는 모델로 나이브 베이스 분류기가 있는데 이는 확률 변수간 의 독립성을 가정하고 관찰된 데이터에 대한 단순한 통계 치에 기반하여 모델의 명시적 확률값을 얼는다. 이 학습방
법은 모든 문서에서 특정 단어의 출현으로 구별되는 이진 속성 벡더로 표헌된 모델로 문서를 정형화 하는데 각 클래 스의 문서마다 다르게 모델을 만들게 된다. 나이브 베이스 가설은 분류 분야에 많이 사용되어 오는 방법으로서 좋은 성능을 가진다. 나이브 베이지안 학습 기법에 따르면 식 (2) 에 의해 각각의 클래스에 대한 문서의 조건부 확률값을 구 하고, 구해진 확률 값 중 가장 높은 확률 값올 가진 클래스 로 문서를 분류하게 된다. 이 학습 기법을 다충 에이전트의 협상 분야에 사용하게 되었으며 Bazzar라는 시스템은 연속 적인 에이전트간의 헙상 과정에서 가격과 질, 운송수단 등 의 오소들을 베이지안 학습 네트워크로 구성하여 베이지안 믿음 갱신을 통해 협상과정을 학습한 시스텝이다.

$$
\begin{array}{r}
\left(p \mid d_{j}\right)=X_{t=1}^{\mathfrak{n}}\left(B_{t} P\left(w_{t} \mid c_{j}\right)+\left(1-B_{t}\right)\left(1-P\left(w_{t} \mid c_{j}\right)\right) \quad(2)\right. \\
\text { 나이브 베이지안 }
\end{array}
$$

\section{4. 시스템 설계 및 구현}

\section{1 서스템 설계}

\section{1 .1 기본 가정}

$\mathrm{CRM}$ 환경에서 하나의 에이전트가 동료와 협조하여 일을 처리하기에 적합한 상황을 결정하는데 나이브 베이지안학습 법을 적용한다. 시스템의 상황 결정을 위해 고려해야 할 환 겅요소로는 첫째, 처리해야 하는 문서는 문서 전체를 나터내 는 것이 아니라 문서의 처리해야 하는 부분만을 나타낸다.

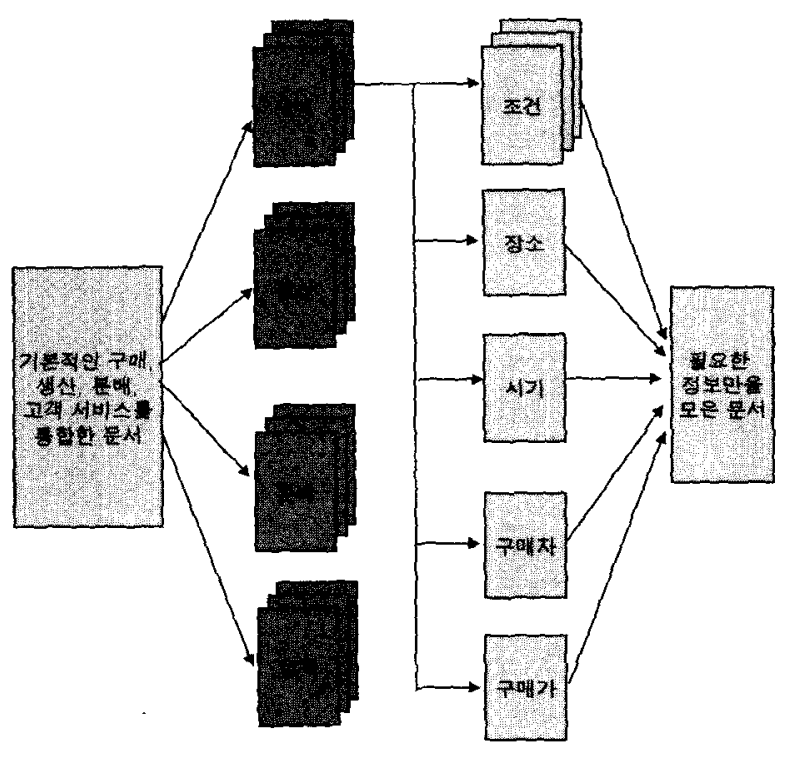

(그림 3) 파일의 수집과 분류

둘째로는, 처리해야 할 내용의 분류 작업은 기계학습에 기초 하여 각각의 해당 문서 내용을 분석함으로써 이루어진다. 
4.1 .2 파일의 분류와 수집

파일은 기본적으로 구매, 생산, 분배, 고객 서비스를 포함 한 통합 문서를 가지고 파일을 자기가 원하는 형태로 분류 를 하게 된다.

\section{1 .3 특징 추출 및 모델화}

특징 추출은 학습 자원의 중요 속성들을 자원이 구분된 클래스별로 다시 한번 중요도를 정의하는 특징 추출 학습 법을 사용하기 위하여 각 자원들의 고려하여 구분된 클래 스들을 대상으로 일련의 구별 작업을 두어 이를 기반으로 한 속성 추출을 수행할 필요가 있다. 이러한 학습 법은 카 테고리를 대표하는 더욱 높은 가중치를 주는 것이다.

\section{2 실험측정}

본 논문에서는 전자 상거래상에서 일어나는 구매, 생산, 분 배, 고객 서비스를 대상으로 한 파일의 분류 작업을 효율적으 로 수행하기 위해 나이브 베이지안 학습 기법을 사용하였다.

분류 대상의 파일을 클래스 당 5 개씩 40 개로 정하고 나 이브 베이지안 학습 기법에 따른 분류 성능을 훈련 예제의 실행 횟수를 변화하면서 측정한 결과 실행 횟수가 많을수 록 검색을 정확하게 한다는 사실이다.

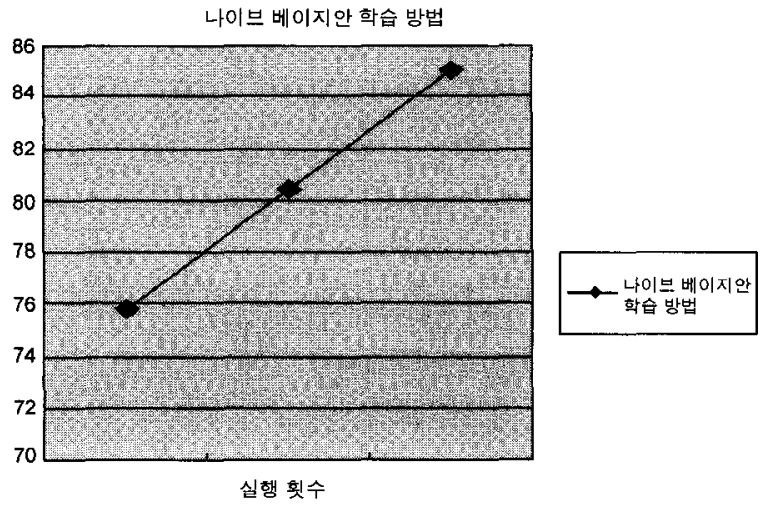

(그림 4) 성능 그래프

\section{5. 결 론}

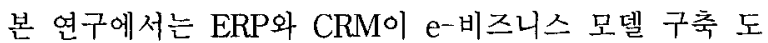
구가 되기 위해 갖추어야 할 기능들에 대해 탐색하는 연구 목적에 따라 확장된 $\mathrm{ERP}$ 모델을 중심으로 개넘을 정리하였 고 최근 기업들이 추진하고 있는 $\mathrm{e}^{-}$비즈니스 모델의 개념 과 기능들을 살펴 보았다. 특히 $\mathrm{e}^{-}$비즈니스 모델에서 유통 망관리(SCM)시스템은 $\mathrm{BtoB}$ 기반으로, 그리고 통합고객관리 (CRM) 시스템은 $\mathrm{BtoC}$ 기반으로 제시되었다. 또한 $\mathrm{ERP}$ 와 $\mathrm{CRM}$ 에서의 에이전트의 역할에 대해 살펴 보았다.

이러한 시스템이 최근 급격히 부상하고 있는 $\mathrm{e}^{-}$비즈니스 도입방안으로 적용되기 위해서는 보안문제, 지불시스템 기 능 및 웹 판매와 같은 전형적인 전자상거래시스템 기능을 추가하거나 이를 수용하기 위한 인터페이스 기능이 보완하 기 위하여 에이전트 개념을 도입하여 보았다. 본 논문의 시 스템 특징은 기존에 수작업으로 이루어지던 파일의 분류 작업을 에이전트가 자동으로 수행함으로써 사용자가 좀 더 효율적으로 작업을 수행할 수 있도록 하였다.

본 연구는 연구 성격상 문헌연구에 초점을 맞추었다는 점에서 다음과 같은 연구시사점을 준다. 첫째, $\mathrm{ERP}$ 패키지 들에 대한 $\mathrm{e}^{-}$비즈니스 관련 기능에 대한 실증적 연구, 둘 째, $\mathrm{e}^{-}$비즈니스 관련 네트워크 보안, 지불시스템 및 웹 판 매 등에 대한 현황조사, 셋째, 본 연구의 타당성 검증을 위 한 실증적 연구 등이 후속적으로 이루어져야 할 것이며, 좀 더 효율적인 에이전트 연구가 이루어져야 할 것이다.

\section{참 고 문 헌}

[1] 조남재, 노규성, 경영정보시스템-전략적 비전 실현을 위한 접 근법-, 세영사, 1998.

[2] 이동길, $\mathrm{ERP}$ 전략과 실천, 대청, 1999.

[3] 이상훈, “최적의 기업환경을 구축하는 정보 대동맥-ERP", ORACLE Magazine, pp.28-35, Fall, 1998.

[4] 이재규, 전자상거래 원론, 법영사, 1999.

[5] 노규성, erp 패키지의 기능적 구성, 정보처리학회지, Vol.6, No.5, Sep., 1999

[6] IBM, e-비즈니스 세미나 자료, 2000.

[7] Licker, Paul S., Management Information Systems : A Strategic Leadership Approach, The Dryden Press, 1997.

[8] http://www.nca.com.

[9] http://www.oracle.com.

[10] Hyacinth S. Nwana, Software Agents : An Overview, Cambridge University Press, 1996.

[11] S. J. Park, et al., "Emergent Properties of A Market-Based Digital Library with Strategic Agents," Proc. of ICMAS-98, 1998.

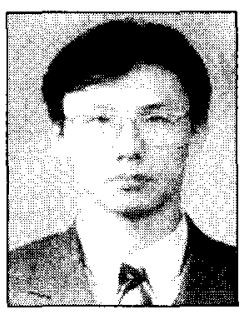

관심분야 : $\mathrm{ERP}, \mathrm{KM}$, 전자상거래 등 e-mail : mischang@incheon.ac.kr 1989년 순천향 대학교 전잔계산학과(학사) 1991년 연세대학교 전자계산학전공(석사) 2001 년 경기대학교 전자계산학과(이학박사) 2003년 현재 인천대학교 정보기술대학 초빙교수 


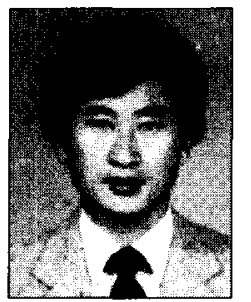

\section{이 정 배}

e-mail : jblee@sunmoon.ac.kr

1981 년 경북대학교 전자공학과 전자계산 전공 공학사

1983년 경북대학교 대학원 전자공학과 전자계산전공 공학석사

1995년 한양대학교 대학원 전자공학과 정보통신전공 공학박사

1982년 1991년 한국전자통신연구원 선임연구원

1991년 2002년 부산외국어대학교 컴퓨터·전자공학부 부교수 2002년 현재 선문대학교 컴퓨터정보학부 부교수

관심분야 : 실시간 시스템, 임베디드 시스템, 실시간 통신 프로 토콜

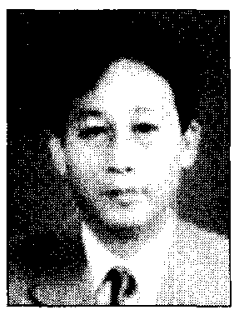

\section{이 병 수}

e-mail : bsl@incheon.ac.kr 1999년 경기대학교 전자계산학과

(이학박사)

1981년 현재 인천대학교 교수

관심분야 : 소프트웨어 공학, 전자상거래 